\title{
Bioassay Guided Fractionation and Anti-Trypanosomal Effect of Fractions and Crude Aqueous and Methanolic Extracts of Terminalia Avicennioides (Guill. \& Perr.) Parts
}

\author{
Sunday E. Atawodi (Corresponding author) \\ Department of Biochemistry, Ahmadu Bello University, Zaria, Nigeria \\ Tel: 234-8033-850-613_E-mail: atawodi_se@yahoo.com \\ Timothy Bulus \\ Department of Biochemistry, Ahmadu Bello University, Zaria, Nigeria \\ Mohammed Mamman \\ Department of Veterinary Physiology and Pharmacology \\ Ahmadu Bello University, Zaria, Nigeria
}

Received: October 9, 2010 Accepted: October 26, 2010 doi:10.5539/ijb.v3n3p19

*Participated in this study as a postgraduate student in 2003/2004

\begin{abstract}
In vitro and in vivo anti-trypanosomal effects as well as reagent-based chemical screening of the aqueous and methanolic extracts of the roots, leaves and stem bark of Terminalia avicennioides were undertaken. In vitro, cessation or drop in the parasite motility, compared to the control, was taken as a measure of the anti-trypanasomal efficacy of the extracts following incubation of the parasite, Trypanosoma brucei brucei, with different extract concentrations $(0,5,10$ and $20 \mathrm{mg} / \mathrm{ml})$ in 96-well micro titre plate. In vivo, groups of infected white albino rats were treated with 50,100 and $200 \mathrm{mg} / \mathrm{kg}$ and the effect of treatment on parasitemia, packed cell volume (PCV) and lifespan were monitored. The root and stem bark extracts completely immobilized trypanosomes within 30 minutes of incubation at $20 \mathrm{mg} / \mathrm{ml}$ concentration, with the aqueous root extract displaying the highest activity, and the methanol extract of the leaf, the least. This effect compared favorably with that of the standard drug, diminazine aceturate. In vivo, significant $(\mathrm{P}<0.05)$ suppression of parasitemia, alleviation of anemia and prolongation of lifespan occurred in a dose dependent fashion with both the crude extracts and the bioassay-guided fractions. Reagent-based chemical analyses of the crude extracts showed presence of anthraquinones, tannins, saponins, flavonoids and cardiac glycosides, but the ethylacetate: methanol fraction which was most active revealed strong presence of saponins. These results suggest that the use of Terminalia avicennioides for management of trypanosomiasis in traditional medicine has scientific basis, and thus warrants further detailed evaluation.
\end{abstract}

Keywords: Anti-trypanosomal effect, Bioassay-guided fractionation, Phytochemical analyses, Terminalia avicennioides, Trypanosoma brucei brucei

\section{Introduction}

Trypanosomosis, popularly known as trypanosomiasis, is a parasitic disease affecting man and his domestic animals. The disease is caused by a single-cell protozoa parasite of the genus Trypanosoma. In human, Trypanosoma brucei gambiense and Trypanosoma brucei rhodesiense cause sleeping sickness in tropical and subtropical Africa while in South America, Trypanosoma cruzi is the causative organism of Chagas disease. Animal trypanosomosis (nagana), on the other hand is caused by $T$. b. brucei, T. congolense and T. vivax. An estimated population of 10 million animals and 300,000 to 5000,000 people were reported to be infected with $T$. cruzi and human African trypanosomes, respectively (Fairlamb, 1982; Seed, 2000). Trypanosomosis of domestic 
animals is responsible for the death of about 3 million cattle annually which is accompanied by an estimated $20 \%$ decrease in calving and $25 \%$ decrease in milk production (WHO, 1975). These have restricted land use and prevented some of the otherwise, most favorable agricultural lands of sub-saharan Africa from being developed (Barry, 1976).

The chemotherapy of African trypanosomosis is faced with a number of problems. First, the number of available drugs for the treatment of secondary stage trypanosomosis is limited (Barry, 1976). Second, drugs like melarsoprol have been demonstrated to result in increasing number of relapses (Poltera et al., 1981). Furthermore, even trypanocides that are known to be effective in the treatment of the secondary stage of the infection (e.g. organic arsenicals) are unfortunately very toxic (Kuzoe, 1993). These problems together with the associated expensive nature of most drugs in developing nations with poor economic status, makes the searching for better and cheaper trypanocides an absolute necessity.

For long, medicinal plants have been used traditionally to treat various kinds of diseases (Nwude and Ibrahim, 1980; Farnsworth et al., 1985; Malekzadeh et al., 2001) and today about $80 \%$ of the world's population relies mainly on traditional medicine for their primary health care needs (Akerele, 1993). Hence, it seems rather justified that the research for new and improved plants-derived drugs for the treatment of trypanosomosis should be further intensified.

Terminalia avicennioides (Guill. and Perr.) is a tropical plant with extensive medicinal applications (Adewunmi and Sofowora, 1980; Abdullahi et al., 2001). It is called 'baushe' in the Hausa language of Northern Nigeria. Our survey in the early part of this decade (Atawodi et al., 2002) revealed that the aqueous extract of its stem bark is traditionally employed to treat sleeping sickness. Subsequent screening of the methanol extract of this plant suggested potent anti-trypanosomal activity (Atawodi et al., 2003). Therefore, this work was designed to further explore the in vivo anti-trypanosomal potential and identify the major classes of phytochemicals present in Terminalia avicennioides.

\section{Materials and Methods}

\subsection{Plant sample}

Different parts of Terminalia avicennioides were collected from Tashan-Fulani village in Zaria, Kaduna State, Nigeria. The plant's identity was confirmed at the Herbarium Section of the Department of Biological Sciences, Ahmadu Bello University, Zaria, Nigeria, where a specimen with Voucher Number 900239 was deposited.

\subsection{Animals}

White albino rats weighing $100-150 \mathrm{~g}$ and twenty albino mice weighing between 15 and $20 \mathrm{~g}$ were obtained from the Nigerian Institute for Trypanosomiasis Research (NITR) Vom, Plateau State, Nigeria. The animals were fed ad libitum on tap water and diet specially prepared from chick grower's mash (Pfizer Ltd, Lagos, Nigeria).

\subsection{Test parasite}

The parasite (Trypanosoma brucei brucei) was obtained from the Department of Veterinary Parasitology and Entomology, University of Nigeria, Nsukka. The parasite was isolated from a hunting dog in March, 2002 and until 2003 when the experiment was performed, maintained in laboratory rats by continuous passage.

\subsection{Plant extraction}

Fresh leaves, stem and root bark of Terminalia avicennioides were cut into small pieces and then dried under shade for about a week, until they became brittle. Exactly $200 \mathrm{~g}$ of pounded dried sample was boiled in 1 liter of distilled water contained in a conical flask for one hour. Thereafter, extract was filtered hot through muslin cloth and then with Whatman filter paper. The filtrate was dried on a water bath at $50^{\circ} \mathrm{C}$, and stored in a refrigerator at $4^{\circ} \mathrm{C}$ until required. The methanol extracts were prepared by maceration for 24 hour and filtrate also dried at $50^{\circ} \mathrm{C}$ on water bath.

\subsection{Bioassay-guided fractionation of T. avicennioides stem bark extract}

The crude aqueous extract of $T$. avicennioides stem bark (one of the most active extract) was fractionated on silica gel packed into a $1.5 \times 30 \mathrm{~cm}$ column. The column was eluted with four solvent-mixtures (ethylacetate/methanol, 19:1; benzene/methanol, 9:1; acetic acid/methanol, 1:1 and water/methanol, 1:1) in order of increasing polarity. The eluates were collected in separate beakers and made to dry at $50^{\circ} \mathrm{C}$ in water bath. The dried fractions were kept at $4{ }^{\circ} \mathrm{C}$ until required.

\subsection{Estimation of trypanosome parasite in blood}

The parasites in the blood were estimated according to the rapid "matching" method of Herbert and Lumsden 
(1976) as described by Atawodi et al (2003), Atawodi (2005). The method employs a matching technique in which microscopic fields were compared with a range of standard logarithmic values. To count the number of parasites in blood, a drop of blood was obtained on a slide by pinching the tip of the pre-sterilized tail with a sterile needle, immediately covered with a cover slip, and the wet mount observed under x 400 magnification. The number of trypanosomes per microscopic field was then compared with the table of logarithmic values. The logarithm values which matched the microscopic observation were then converted to antilogarithm, from where the absolute number of trypanosomes per ml of blood was obtained.

\subsection{In vitro anti-trypanosomal effect of crude extracts and fractions of T. avicennioides}

Infected rats were sacrificed at high parasitemic state, and the blood collected in Eppendorf tubes containing 0.2 $\mathrm{ml}$ of 1\% EDTA prepared with phosphate buffered saline (PBS). The aqueous extract of the stem bark and the standard drug were dissolved in PBS while the methanolic extracts were first dissolved in $10 \%$ dimethylsulfoxide in PBS, and then further diluted with PBS to bring DMSO concentration to $1 \%$. For all the extracts/drug three sets of concentrations $(0,5,10$ and $20 \mathrm{mg} / \mathrm{ml})$ were prepared by serial dilution. The in vitro experiment involved incubating $40 \mu \mathrm{l}$ of infected blood with $10 \mu \mathrm{l}$ of extract solution in a 96-well microtitre plate to produce effective test concentrations of $0,1,2$ and $4 \mathrm{mg} / \mathrm{ml}$, respectively. Five microlitres of the mixture were immediately placed on a slide and covered with a cover slip and the parasite's motility monitored microscopically against control wells containing no extract (negative control) or equal concentration of the standard drug (positive control) at 5 minutes intervals for a period of one hour. Since motility constitutes a relatively reliable indicator of viability among most zooflagellate parasites (Peter et al, 1976), cessation or drop in the motility of trypanosomes was used as a measure of anti-trypanosomal effect of plant extracts and the standard drug, under in vitro condition.

\subsection{In vivo evaluation of the anti-trypanosomal activity of T. avicennioides extracts}

Thirty male albino rats were used for this experiment. The animals were separated into six groups of 5 animals each. Animals in group 1 were left as negative control group (administered only $0.3 \mathrm{ml}$ PBS). Animals in the remaining groups $(2,3,4,5$ and 6$)$ were all infected with about $10^{4}$ parasites each. Group 2 was then left as a positive control group (infected but not treated). Animals in groups 3, 4, 5, and 6 were each treated with 3.5 $\mathrm{mg} / \mathrm{kg}$ of diminazine aceturate, 50,100 and $200 \mathrm{mg} / \mathrm{kg}$ of the crude aqueous extract, respectively. The treatment was commenced four days post infection (when parasitemia was 1-2 per microscopic field) and lasted for six days. All the animals were monitored daily for parasitemia throughout the course of the experiment. In addition, five sets of blood samples were obtained from tails of animal into capillary tubes (on day $0,4,10,14$ and 28 ) for determination of Packed Cell Volumes (PCV).

\subsection{Packed cell volume determination}

Blood samples collected into heparinized capillary tubes with one end of each tube sealed with plasticine or a Bunsen flame were spunned at $2000 \mathrm{~g}$ for five minutes in a microhaematocrit centrifuge. The packed cell volumes (PCVs) were determined with the aid of a micro-haematocrit reader, and the values expressed as percentages (Barbara, 1980).

\subsection{Reagent-based chemical screening of extracts and column fractions of T. avicennioides}

The crude aqueous extracts and column fractions $T$. avicennioides stem bark were subjected to standard reagent-based phytochemical tests for six major constituents, namely: tannins, saponins, alkaloids, anthraquinones, glycosides, flavanoids (Sofowora, 1982; Trease and Evans, 1983).

\subsection{Statistical analysis}

Data was analyzed by ANOVA and student t-test using Statistical Package for Social Sciences (SPSS-computer package). For all evaluations, the level of statistical significance was fixed at $\mathrm{p}<0.05$

\section{Results}

\subsection{In vitro anti-trypanosomal evaluation of crude extracts of T. avicennioides and fractions}

Table 1 shows the in vitro effect of various concentrations of aqueous and methanol extracts of three different parts (stem, root and leaf) of Terminalia avicennioides on the motility of T. brucei brucei. Like with the standard drug, the parasites were completely immobilized within 30 minutes of incubation with stem and root aqueous. For the leaf extracts, cessation of motility was not seen throughout the incubation period. Overall, highest activity was found with root aqueous extract while the least was observed with the leaf extracts. The methanolic extracts of the leaf gave a similar pattern of anti-trypanosomal activity, but even to a lesser extent, as there was no noticeable change in motility. When fractionated, fraction 1 (ethylacetate/methanol fraction produced the 
most significant in vitro effect on trypanosomal motility which was comparable to that of the control, while acetic acid: methanol fraction (fraction 3) showed moderate activity, and Fraction 24 showed very little activity at the highest concentration of $20 \mathrm{mg} / \mathrm{ml}$ (Table 2).

\subsection{Packed cell volume and parasitemia in animals administered T. avicennioides extracts and column fractions}

There was a drop in the mean \% PCV levels with increasing infection. The decrease was significant $(\mathrm{P}<0.05)$ by day 14 (in the untreated control group). An inverse relationship was observed between packed cell volume and parasitemia $(r=-0.77$; Figure 1), suggesting that hemoglobin concentration decreases with increasing severity of infection. However, treatment with the extracts alleviated anemia by improving the packed cell volume in a dose-dependent manner, but not above the critical level, except the group on standard drug (Figure 2).

\subsection{In vivo anti-trypanosomal effect of aqueous extract of $T$. avicennioides and fractions}

Figure 3 gives the parasitemia pattern among three groups treated with different doses of the aqueous extract of the bark and the standard drug. Four days after commencing treatment, significant $(\mathrm{P}<0.05)$ dose-dependent suppression of parasitemia was observed, with the highest dose level $(200 \mathrm{mg} / \mathrm{kg})$ wiping the parasites from the blood stream within three days, while the diminazine-treated animals were cleared of their infection after two days of treatment. Relapse was, however, observed after 4 weeks, in two of the five animals in the group. Also, in vivo evaluation with fractions showed that while fractions 1 (ethyl acetate: methanol) at $150 \mathrm{mg} / \mathrm{dose}$ significantly $(\mathrm{P}<0.05)$ suppressed parasitemia, fraction 3 (acetic acid-methanol group) did not suppress parasitemia significantly $(\mathrm{P}>0.05)$, when compared to the untreated group (Figure 4$)$.

3.4 Effect of administration of aqueous extract and fractions on $T$. avicennioides on lifespan of trypanosome-infected rats

In the untreated control group, all animals died within 14 days after infection, but in the diminazine-treated control group, animals remained alive for the two months of observation. The mean lifespan of animals in all the extract-treated groups (Figure 5) slightly exceeded that in the infected but untreated control group. The mean lifespan of rats on diminazine group was not significantly different $(\mathrm{P}>0.05)$ from that of the uninfected control group (Figure 5). Furthermore, the mean lifespan of mice treated with fraction 1 was only slightly but non-significantly $(\mathrm{P}>0.05)$ extended over those of animals treated with fraction 3 (Figure 6).

\subsection{Reagent-based phytochemical Screening of Crude Extracts and fractions of T. avicennioides stem bark.}

Reagent-based phytochemical screening of the crude aqueous extracts and column fractions of $T$. avicennioides revealed the presence of flavonoids, tannins, saponins and anthraquinones (Table 3). The major difference between the crude aqueous extract and its fractions is with their levels of flavonoids and saponins. There was, however, a strong variation among the column fractions, with the saponins largely pooled into the ethylacetate/methanol fraction (Table 4).

\section{Discussion}

White albino rats were susceptible to infection with the strain of Trypanosoma brucei used and picked up the infection as early as day four, post infection. The infection lasted two weeks and terminated with $100 \%$ mortality in infected but untreated controls. Anemia depicted by drop in PCV values was found to accompany the rising wave of parasitemia in the course of the disease. Packed cell volume was negatively correlated with parasitemia (Figure 1). The strong negative value of the coefficient of correlation $(\mathrm{r}=-0.773)$, indicates a strong inverse relationship between PCV and parasitemia implying that increase in parasitemia, strongly decreases the packed cell volume of the diseased animals.

This agrees with observation in mice experimentally infected with T. brucei (Igweh and Onabanjo, 1989). Anemia observed in this study is in agreement with data from a vast number of studies (Fiennes, 1954; Jenkins et $a l, 1980)$. Several theories have been put forward to explain this inverse relationship. Prominent among these is the postulation that dead and dying trypanosomes release hemolytic factors into the animal's blood (Anosa and Kaneko, 1983a; Emmanuel et al, 1999; Esievo, 1983; Mellors and Samad, 1989). As the parasites divide, increasing blood parasite population, and consequently giving rise to more dead parasites, more of the hemolytic factors are produced leading to increased destruction of erythrocytes, and hence the reduction in PCV. The observed reduction in red cell counts is in consistent with the observed anemia.

In vitro, the extracts from root and stem rendered the parasites completely immotile within 35 minutes of incubation at extract concentration of $20 \mathrm{mg} / \mathrm{ml}$ (Table 1) and the extract's activity was comparable to that of diminazine aceturate, a standard drug whose mechanism of action is already established (Gutteridge and Coombs, 1977). The leaf extracts, however, did not affect the parasite's motility to any significant degree. The difference 
in anti-trypanosomal activities of extracts from various parts of the plants tested is attributable to variation in types and amount of phytochemicals present in them (Tables 3 and 4).

In vivo, the crude aqueous extract was found to significantly suppress the parasitemia after six days of consecutive administration in a dose-dependent manner (Figure 3). Column fractions of the crude extract produced highest in vitro activity in the least polar fraction, ethylacetate: methanol, followed by acetic: methanol fraction (Table 2). When both fractions were tested in vivo, again only ethylacetate: methanol fraction, presented similar parasitemia pattern (Figure 4) with that of the crude (Figure 3). Hence, anti-trypanosomal principle of the aqueous extract appears to reside in the least polar ethylacetate/methanol fraction, with the saponins as the sole or major active ingredient. The relapse seen in $200 \mathrm{mg} / \mathrm{kg}$ dose group after the parasites were completely wiped out of the blood for 3 days, could be as a result of resistance put forward by the parasites or some limitations on the part of the extract itself such as the inaccessibility of the extract to other tissues where the flagellates are known to hide as a way of evading trypanolytic action of drugs (Anosa, 1988). It is also possible that the active component may be of short half life making it unable to stay in the blood medium in sufficient amount long enough to exert its properties on the parasites, completely. The possibility that the active component is only trypanostatic rather than trypanocidal, must also be seriously considered.

While it is possible that parasites could still be found in other organ(s) even after their disappearance from the blood (Anosa, 1988a), it seems that their presence and rapid proliferation in the blood are very important in the disease process. Any chemical substance that is able to delay the appearance of the parasites in the blood will concomitantly delay the manifestation of some pathological lesions. Sustained suppression of this parasitemia would have, no doubt, alleviated the anemia observed with infected rats since parasitemia is one of the several factors implicated in the mechanism of anemia in human and animal trypanosomosis (Fiennes, 1954; Jenkins et al., 1980; Esievo, 1983; Anosa and Kaneko, 1983b). The alleviation of the anemia may explain the significantly $(\mathrm{P}<0.05)$ increased lifespan of the animals treated with the extract, extract fractions or the standard drug (Figure 5 and Figure 6).

The results of the reagent-based phytochemical screening agree with those seen in aqueous root extract of Terminalia avicennioides by Abdullahi and his colleagues (2001). Reagent-based chemical analysis of T.avicennioides fractions (1and 3) suggested that saponins are largely pooled and concentrated in the ethylacetate/methanol fractions which proved most active, both in vitro and in vivo. Even though this fraction tested positive for other compounds (tannins and anthraquinones) the fact that other fractions containing tannins and anthraquinones, but not saponins were at best, only weakly active, suggest that the variation in the anti-trypanosomal efficacy in vivo can only logically be attributed to this difference in the concentration of saponins. Therefore, it is hypothesized, that the trypanocidal potential of the aqueous extract of Terminalia avicennioides stem bark may be due to its high content of saponins, or the interaction of this major component with other minor phytochemical constituents. Further work is however required to confirm this assertion.

Saponins have been reported to possess wide spectrum of antimicrobial activity and their mechanism of action are thought to be by interaction with parasite membrane sterols, proteins and phospholipids (Godwin and Theodore, 2001). It seems plausible to infer that the active ingredient acts as intact glycosides and not as free saponins since preliminary treatment using the oral route did suppress parasitemia. Saponins are not known to be toxic when given orally as they are easily hydrolysed by biotransformation to non-toxic (non-hemolytic) compounds (Trease and Evans, 1983; Sofowora, 1993),

Based on the above, it can be concluded, that the use of Terminalia avicennioides for management of trypanosomiasis in traditional medicine is scientifically justified. However, the relapse observed points to limitations in the use of these extracts alone. But, since most traditional practices consist of herbal concoctions from different plants (Atawodi et al, 2002), it is possible that in such combined herbal therapy involving $T$. avicennioides, the contribution of its aqueous extract is either to suppress the parasitemia and allow active principle from other component of the herbal mixture to easily wipe out the residual $T$. avicennioides- resistant trypanosomes or that the extract is able to interact and weaken the parasites' membrane thereby enhancing the accessibility of organelle-specific active component from other plants in the herbal recipe.

\section{Acknowledgements}

We are grateful to Mr. Gallah Umar of the Herbarium Section, Department of Biological Sciences, for assisting in the plant identification.

\section{References}

Abdullahi, A.L., Agho, M.O., Amos, S., Gamaniel, K.S., \&Wambebe, C. (2001). Antidiarrhooel activity of the 
aqueous extract of Terminalia avicennioides roots. Phytotherapy Research, 15, 431-434

Adewumi, C.O. \& Sofowora, E.A. (1980). Preliminary screening of some plants extracts for molluscicidal activity. Planta Medica, 39, 57-65

Akerele, O. (1993). Nature's medicinal bounty: Don't throw it away. World Health Forum 14, 390-395.

Anene, B.M., Ona D.N., \& Nawa, Y. (2001). Drug resistance in pathogenic African trypanosomes: What hopes for the future? Vet. Parasitol, 96, 83-100

Anosa, V.C. (1988a). Haematological and Biochemical changes in human and animal trypanosomiasis. I Protozoologie, 41 (1), 65-78

Anosa, V.O. (1988b). Haematological and biochemical changes in human and animal trypanosomiasis. Part II Protozoologie, 41 (2), 151-164.

Anosa, V., \& Kaneko, J.J. (1983a). Pathogenesis of Trypanosoma brucei infection in deer mice (Peromyscus maniculatus): Haematologic erythrocyte biochemical, and iron metabolic aspects. American Journal Veterinary Research, 44, 630-644.

Anosa, V. O., \& Kaneko, J.J., (1983b). Pathogenesis of Trypanosoma brucei infection in deer mice (Peromyscus maniculata): Light and electron microscopic studies on erythrocyte pathologic changes and phagocytosis. American Journal Veterinary Research, 44, 645-651

Atawodi, S.E. (2005). Comparative In Vitro Trypanocidal Activities of Petroleum ether Chloroform, methanol and aqueous extracts of some Nigerian Savannah Plants. African Journal Biotechnology, 4(2), 177-182.

Atawodi, S.E., Ameh, D.A., Ibrahim, S., Andrew, J.N., Nzelibe, H.C., Onyike, E.O., Anigo, K.M., Abu, E.A., James, D.B., Njoku, G.C., \& Sallau, A.B. (2002). Indigenous knowledge system for treatment of trypanosomiasis in Kaduna state of Nigeria. Journal of Ethnopharmacolology, 79, 279-28.

Atawodi, S. E., Bulus, T., Ibrahim, S., Ameh, D.A., Nok, A.J., \& Mamman, M. Galadima, M. (2003). In vitro trypanocidal effect of methanolic extract of some Nigerian Savannah plants African Journal Biotechnology, 2(9), 317-321

Barry, B. (1976). An immunological approach. Nature, 260, 380-381.

Babara, A. B. (1980). Hematology: Principles and procedures. Henry Kimpton Publishers, London, pp.71-83.

Clarkson, A.B. \& Brown, F.H. (1976). Trypanosomiasis: An approach to chemotherapy by the inhibition of carbohydrate catabolism. Science, 194, 204-206.

Emmanuel,O.O., Agwu, I. U., \& Kyewalabe, E.K. (1999). Anaemia in experimental African trypanosomiasis. Journal of Protozoology Research, 9: 55-63.

Esievo, K.A.N. (1983). Trapanosoma vivax, stock V953: Inhibitory effect of type A influenza virus anti-HAV8 serum on in vitro Neuraminidase (Sialidase) activity. Journal of Parasitology, 69 (3), 491-495.

Fairlamb, A.H., (1982). Biochemistry of trypanosomiasis and rational approaches to chemotherapy. FEBS Letter, 7 (7), 249-253.

Farnsworth, N.R., Akerele, O., Bingel, S.A., Soejarto, D.D., \& Guo, Z. (1985). Medicinal plants in therapy. Bulletin World Health Organization, 63, 965-981.

Fiennes, N.T.W. (1954). Haematological studies in trypanosomiasis of cattle. Veterinary Record, 66, (30), 423-434.

Godwin, C.E., \& Theodore, N.K. (2001) Phytochemical and antimicrobial properties of constituents of "Ogwu Odenigbo", a popular Nigerian herbal medicine for typhoid fever. Phytotherapy Research, 15, 73-75.

Gutteridge, W.E., \& Coombs, G.H. (1977). Biochemistry of parasitic protozoa. Macmillam Press, London. pp.135-139.

Herbert, W.J., \& Lumsden, W.H.R. (1976). A rapid "matching" method for estimating the host's parasitaemia. Experimental Parasitology, 40, 427-431.

Igweh, A.C., \& Onabanjo, A.O. (1989). Chemotherapeutic effects of Annona senegalensis in Trypanosoma brucei brucei. Annals Tropical Medicine Parasitology, 83, 527-534

Jenkins, G.C., McCRorie, P., Forsberg, C.M., brown, J.L. (1980). Studies on the anemia in rabbits infected with Trypanosoma brucei brucei. The evidence of hemolysis. J. Comparative Patholology, 90: 107-121 
Kuzoe, F.A. (1993). Current situation of African trypanosomiasis. Acta Tropica, 54(3-4), 153-162.

Malekzadeh, F., Ehsanifar, H., Shahmat, M., Levin, M. and Colwell, R.R. (2001). Antibacterial activity of black myrobalan (Terminalia chebula, Retz) against Helicobacter pylori. International Journal Antimicrobial Agents, $18(1), 85-88$.

Mellors, A., \& Samad, A. (1989). The acquisition of lipid by African trypanosomes. Parasitology Today. 5(8), 239-243

Nwude, N. \& Ibrahim, M. A. (1980). Plants used in traditional veterinary medical practice in Nigeria. Journal of Veterinary Pharmacology and Therapeutics, 3, 261- 273

Onyeyili, P.A.,\& Egwu, G.O. (1995). Chemotherapy of African trypanosomiasis: a historical perspective. Protozoology Abstracts, 19 (5), 229-241.

Opperdoes F.R., Aarsen P.N., Vander Meer C. \& Borst P. (1976). Trypanosoma brucei. An Evaluation of salicylhydroxamic acid as a trypanocidal drug. Expermental Parasitology, 40, 198-205.

Peter, D., Honigberg, B.M. \& Fern, A.M. (1976). An improved method of cryopreservation of Trypanosoma (Nannomonas) congolense brooded in liquid nitrogen. Journal of Parasitology, 62(1), 136-137.

Poltera, A.A., Hochmann, A. and Lambert, P.H. (1981). Trypanosoma brucei brucei: the response to melarsoprol in mice with cerebral trypanosomiasis. An immunopathological study. Clinical and Experimental Immunology, (2), $363-374$.

Reitman, S. and Frankel, S. (1957). A colorimetric method for the determination of serum glutamic oxaloacetic and glutamic pyruvic transaminases. American Journal Clinical Pathology. 28, 56

Seed, J.R. (2000). Current status of African trypanosomiasis. ASM News, 66 (7), 395-402.

Sofowora, A. (1993). Medicinal plants and traditional medicine in Africa.Spectrum Books Limited, Ibadan, Nigeria, pp.150-156.

William, C. M., \& Richard, S. D.Jr. (1985). Parasitology. Macmillan Publishing Company, New York. pp. 26-38

Trease, G.E., \& Evans W.C. (1985). Introduction and General Methods. In: Pharmacognosy. $12^{\text {th }}$ Edition, Published by Alden press, Oxford London pp.469-474.

World Health Organization. (1975). Tropical Diseases Today: The challenges and Opportunities WHO Switzerland. Pp 1-10.

Table 1. In vitro anti-trypanosomal effect of aqueous and methanolic extracts of Terminalia avicennioides

\begin{tabular}{|c|c|c|c|c|c|c|c|}
\hline \multirow{4}{*}{$\begin{array}{l}\text { Plant part } \\
\text { tested }\end{array}$} & \multicolumn{7}{|c|}{ motility $\zeta$} \\
\hline & \multicolumn{7}{|c|}{ Plant extracts concentration $(\mathrm{mg} / \mathrm{ml})$} \\
\hline & \multicolumn{3}{|c|}{ Aqueous } & & \multicolumn{3}{|r|}{ Methanol } \\
\hline & 20 & 10 & 5 & & 20 & 10 & 5 \\
\hline Stem & 25 & * & & - & 3 & $*$ & * \\
\hline Root & 30 & * & & - & 0 & $*$ & $*$ \\
\hline Leaf & - & * & & - & 2 & 5 & - \\
\hline \multirow[t]{4}{*}{ Diminal } & 25 & * & & * & 5 & 5 & - \\
\hline & & - & & & - & - & \\
\hline & & * & & & - & - & \\
\hline & & * & & & & & \\
\hline \multicolumn{8}{|c|}{$\begin{array}{l}\zeta \text { Numerical values are indicative of time }(\mathrm{min}) \text { of cessation of motility while '**' and '*' } \\
\text { stand for large and slight decrease in motility after } 60 \text { minutes of parasites incubation } \\
\text { respectively. '-' is used where there was no noticeable effect on the motility. }\end{array}$} \\
\hline
\end{tabular}


Table 2. Effect of Column Fractions of T. avicennioides Aqueous Extract on in vitro Motility of T. brucei brucei

\begin{tabular}{|c|c|c|c|c|c|c|c|c|c|c|c|}
\hline & \multicolumn{2}{|c|}{$\begin{array}{c}\text { Fraction } 1 * \\
\text { Concentration }\end{array}$} & \multicolumn{2}{|c|}{$\begin{array}{c}\text { Fraction } 2 \\
\text { Concentration }\end{array}$} & \multicolumn{2}{|c|}{$\begin{array}{c}\text { Fraction } 3 \\
\text { Concentration }\end{array}$} & \multicolumn{2}{|c|}{$\begin{array}{c}\text { Fraction } 4 \\
\text { Concentration }\end{array}$} & \multicolumn{3}{|c|}{$\begin{array}{c}\mathrm{PBS}^{\dagger} \text { Diminal } \\
\text { Concn. }\end{array}$} \\
\hline & \multicolumn{2}{|c|}{$(\mathrm{mg} / \mathrm{ml})$} & \multicolumn{2}{|c|}{$(\mathrm{mg} / \mathrm{ml})$} & \multicolumn{2}{|c|}{$(\mathrm{mg} / \mathrm{ml})$} & \multicolumn{2}{|c|}{$(\mathrm{mg} / \mathrm{ml})$} & \multicolumn{3}{|c|}{$(\mathrm{mg} / \mathrm{ml})$} \\
\hline & 20 & 10 & 20 & 10 & 20 & 10 & 20 & 10 & 0 & 20 & 10 \\
\hline $\begin{array}{l}\text { Time } \\
\text { motility } \\
\text { ceased } \\
(\mathrm{min})\end{array}$ & 25 & 45 & $>60$ & $>60$ & $>60$ & $>60$ & $>60$ & $>60$ & $>60$ & 25 & $>60$ \\
\hline
\end{tabular}

${ }^{\dagger}$ Phosphate buffered saline

*Fraction 1- (ethylacetate/methanol, 19:1; Fraction 2- benzene/methanol, 9:1; Fraction 3- acetic acid/methanol, 1:1; and Fraction 4-water/methanol, 1:1

Table 3. Class of phytochemical constituents of aqueous and methanolic extracts of the stems, roots and leaves of Terminalia avicennioides (TA)

\begin{tabular}{|c|c|c|c|c|}
\hline & \multirow[b]{2}{*}{ Compounds screened for } & \multicolumn{3}{|c|}{ Plant part } \\
\hline & & Stem & Root & Leaf \\
\hline \multirow{6}{*}{ 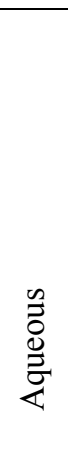 } & Anthraquinone & $+*$ & + & + \\
\hline & Saponin & + & + & - \\
\hline & Tannin & + & + & + \\
\hline & Flavanoid & + & + & - \\
\hline & Alkaloid & - & - & - \\
\hline & Cardiac glycoside & + & + & + \\
\hline \multirow{6}{*}{ 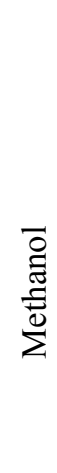 } & Anthraquinone & + & + & + \\
\hline & Saponin & + & + & - \\
\hline & Tannin & + & + & + \\
\hline & Flavanoid & + & + & - \\
\hline & Alkaloid & - & - & - \\
\hline & Cardiac glycoside & + & + & + \\
\hline
\end{tabular}

* The test was positive $(+)$ when compound screened for was detected, negative $(-)$ when it was not found and delta $(\delta+)$ when trace amount was found. 
Table 4. Reagent-based phytochemical screening of the crude aqueous extracts and the active Fractions of Terminalia avicennioides(stem bark)

\begin{tabular}{|l|c|c|c|}
\hline Compounds & Crude extract & Ethylacetate-methanol & Acetic acid - methanol \\
\hline & & (Fract-1) & (Frac-3) \\
\hline Tannins & + & + & + \\
Saponins & + & +++ & $\delta+$ \\
Alkaloids & - & - & - \\
Anthraquinones & + & + & - \\
Glycosides & + & + & - \\
Flavanoids & + & - & + \\
\hline
\end{tabular}

$+\quad$ Indicates presence of the test compound

- Indicates absence of the test compound

$\delta^{+}$Indicates little amount of the test compound

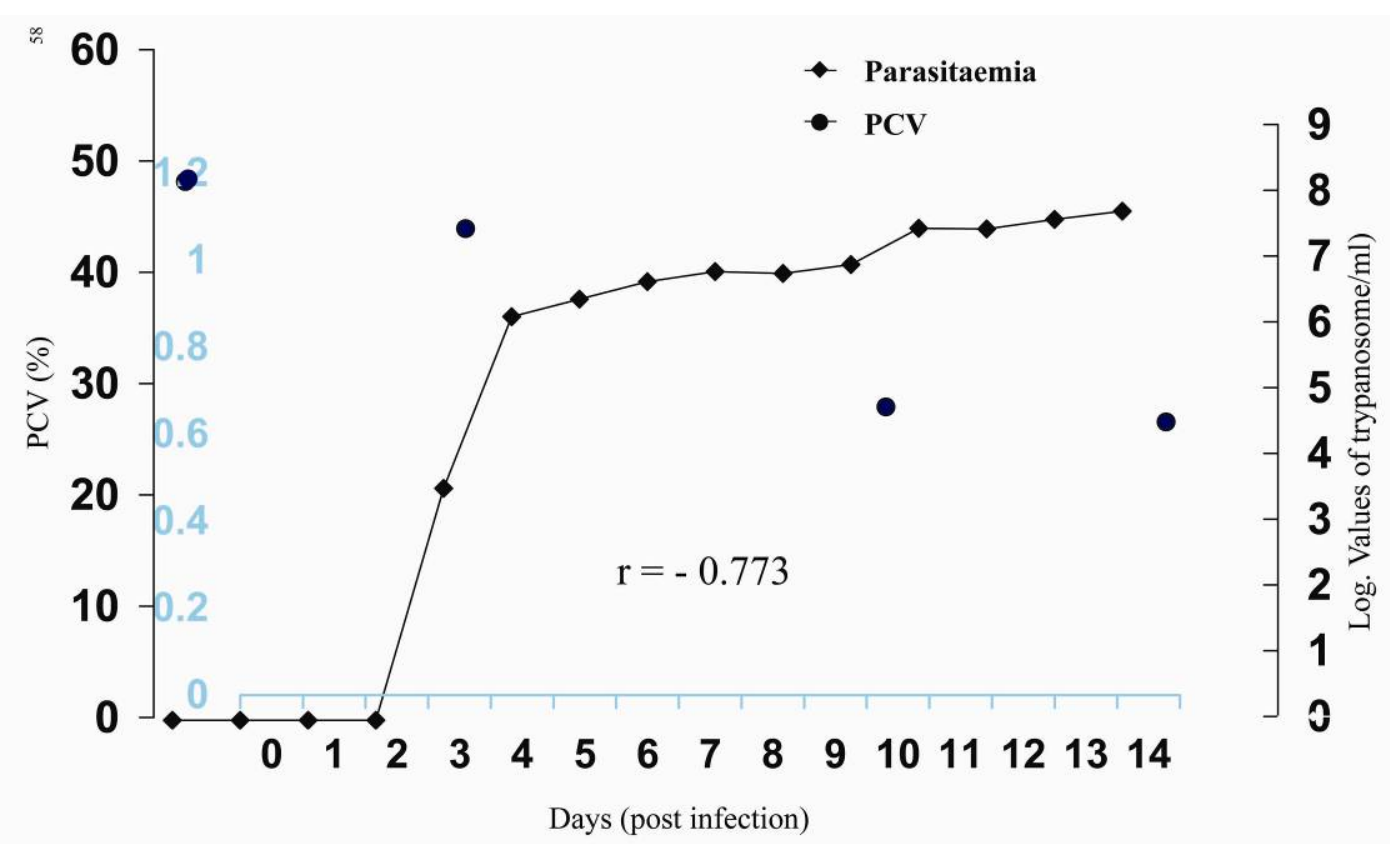

Figure 1. Correlation between PCV and Parasitaemia in Rats infected with T.b. brucei 


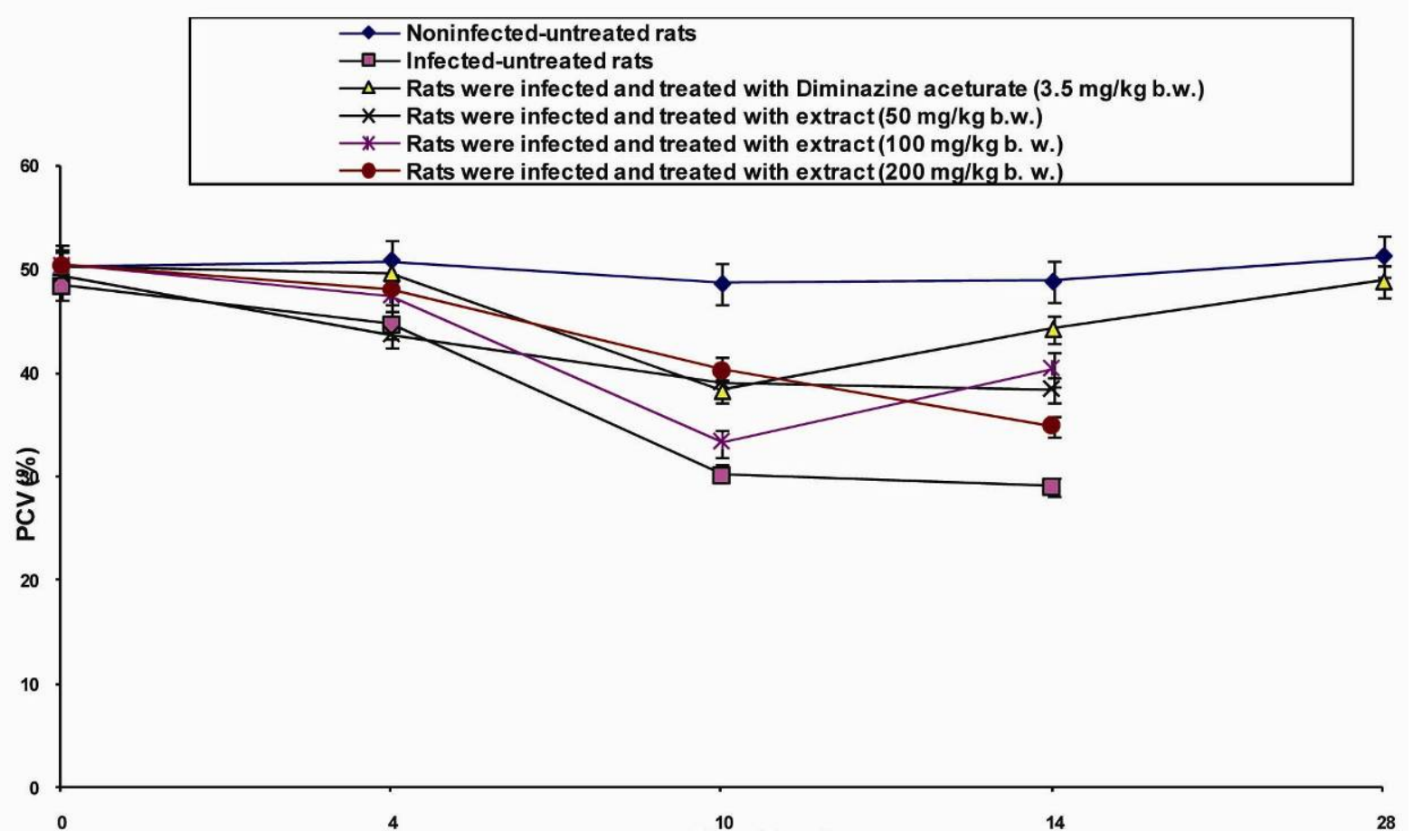

Figure 2. Effect of intramuscular administration of different doses of aqueous extract of T. avicennioides on packed cell volume of rats experimentally infected with

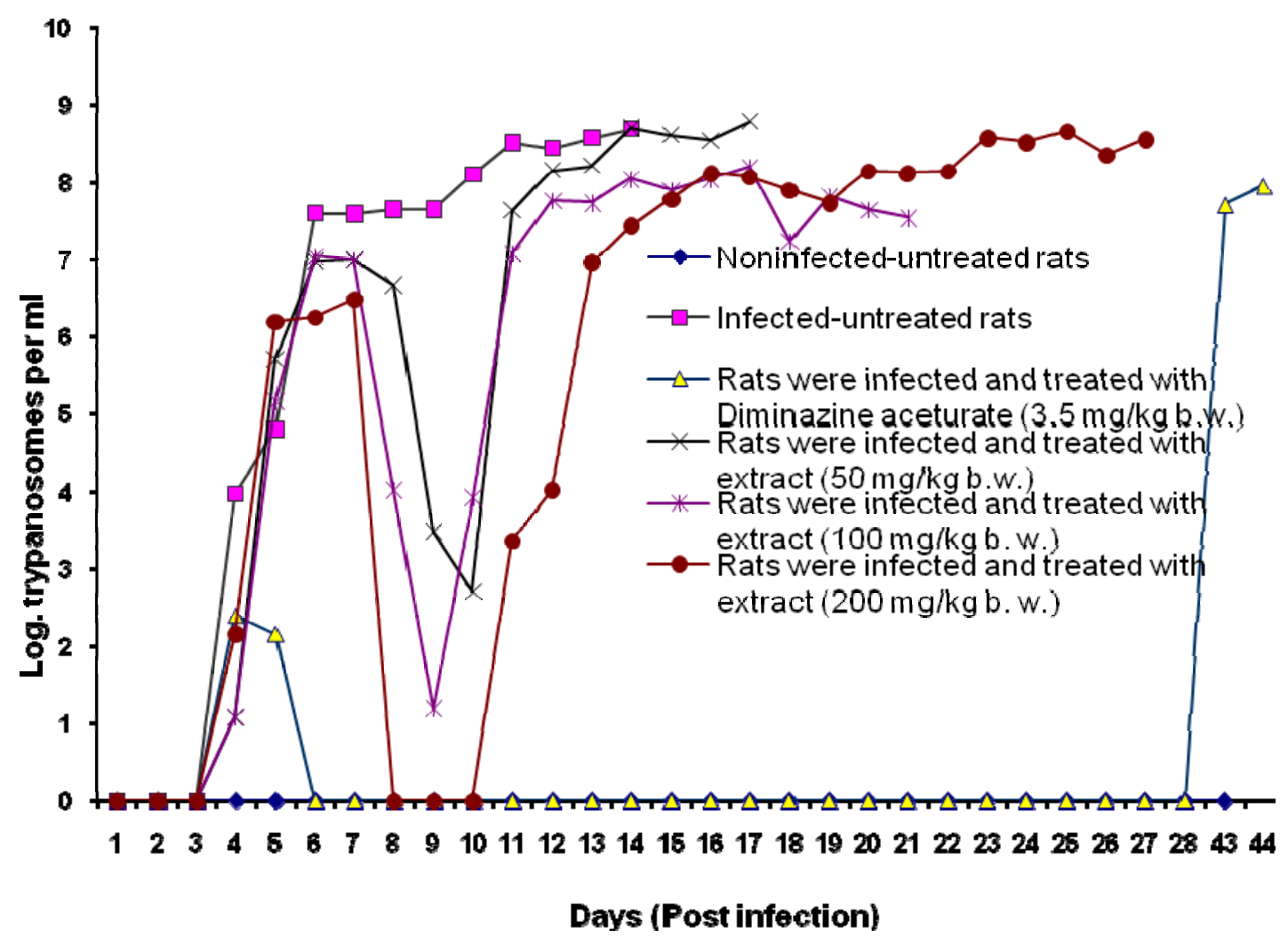

Figure 3. Effect of intramuscular administration of different doses of aqeous extract of $T$. avicennioides on levels of parasitemia in T. brucei brucei-infected rats 


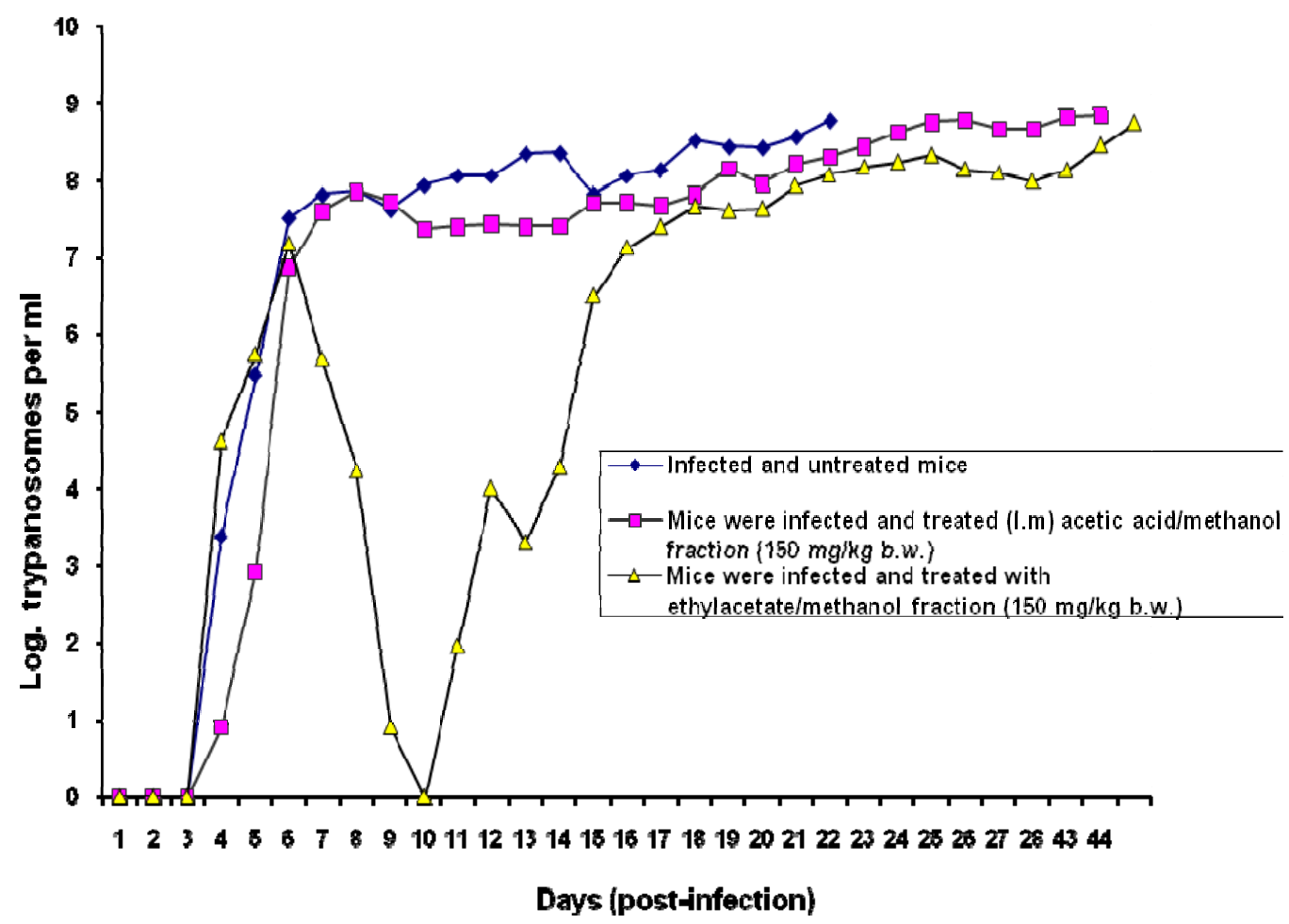

Figure 4. Effect of intramuscular administration of fractions of aqeous extract of T. avicennioides on levels of parasitemia in T. brucei brucei-infected rats

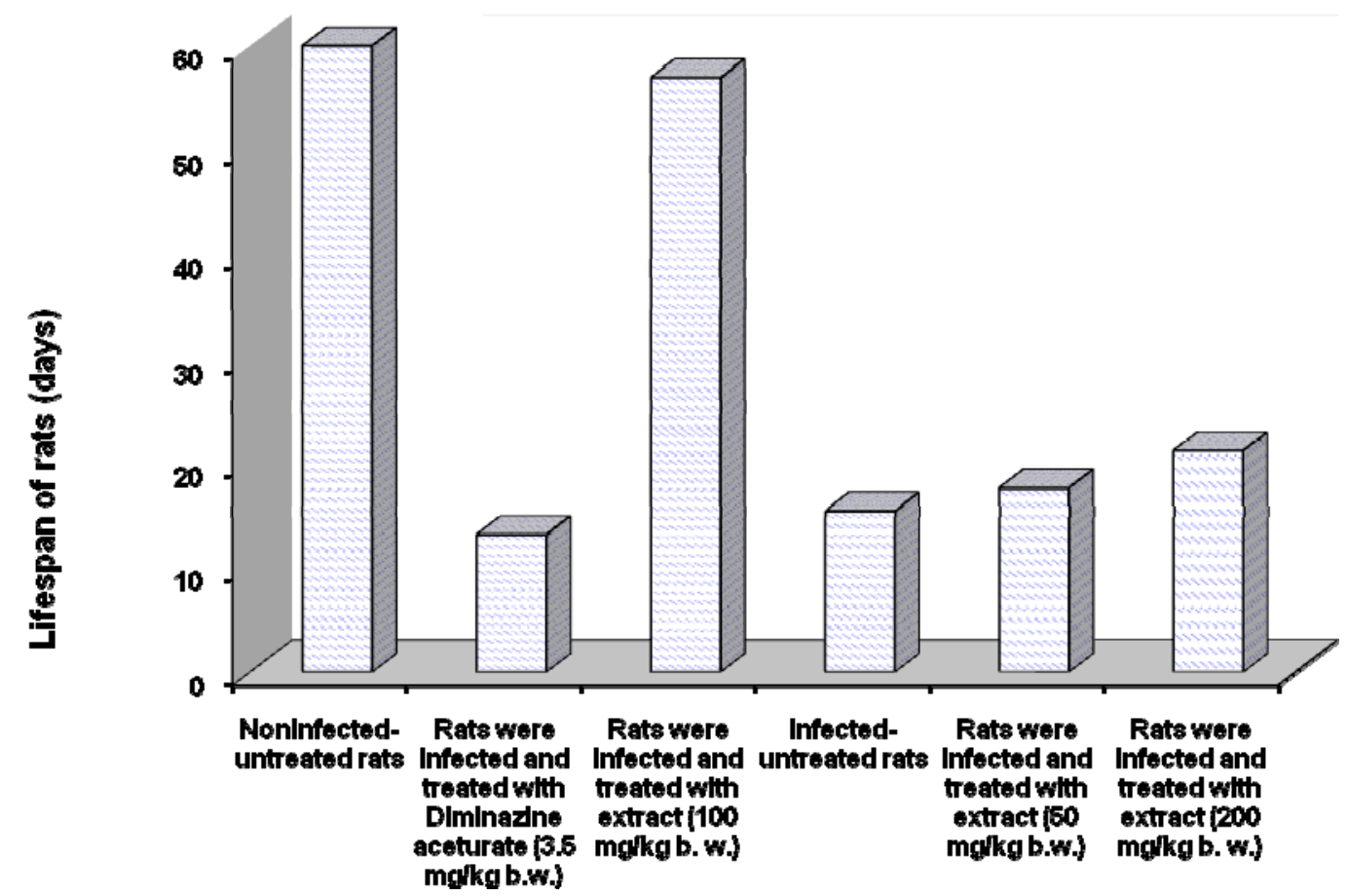

Figure 5. Effect of Intramuscular administration of T. avicennioides aqueous extract on lifespan of rats experimentally infected with T. b. brucei. 


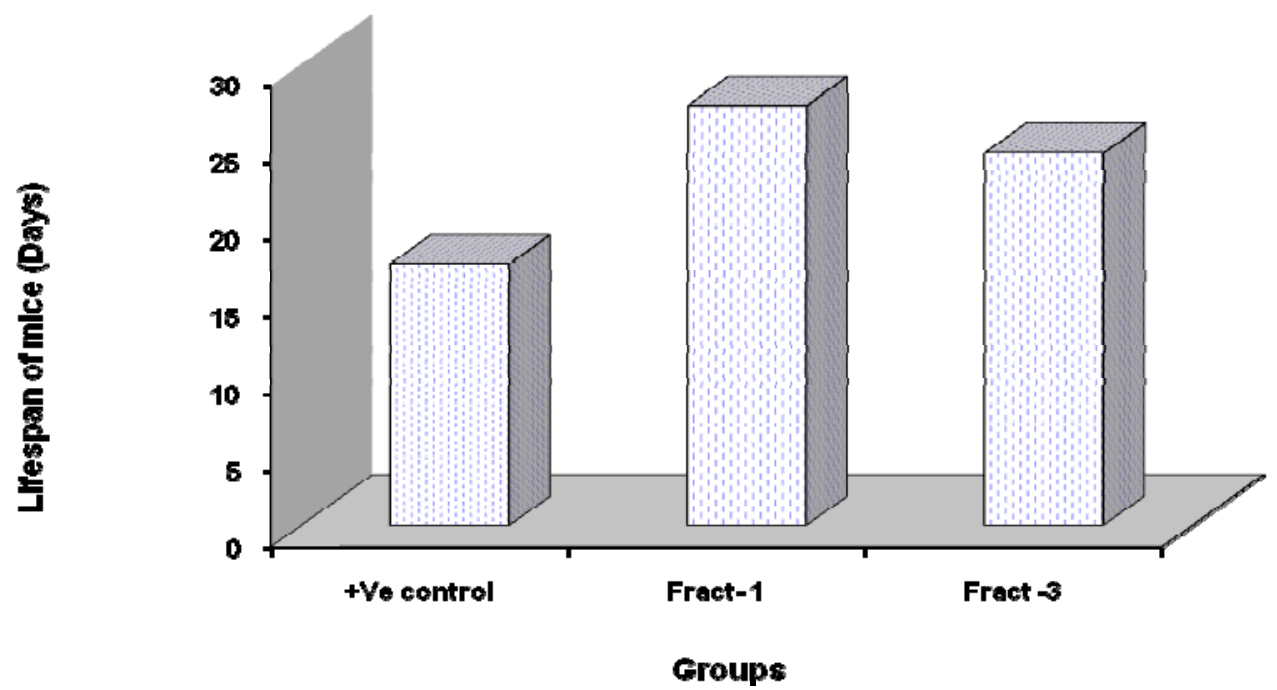

Figure 6. Effect of Intramuscular administration of fractions of T. avicennioides aqueous extract on lifespan of rats experimentally infected with $T$. brucei brucei (+ve control,treated with standard drug diminazine $(3.5 \mathrm{mg} / \mathrm{kg})$; Fract-1, ethylacetate/methanol (150mg/kg); Fract-3, acetic acid methanol(150mg/kg) 